\title{
Correction to: Is there a role for bedside ultrasound in malaria? A survey of the literature
}

\author{
Paolo Malerba $^{1} \cdot$ Daniel Kaminstein $^{2} \cdot$ Enrico Brunetti $^{1,3} \cdot$ Tommaso Manciulli $^{1,4}$ (i)
}

Published online: 22 August 2019

(c) Società Italiana di Ultrasonologia in Medicina e Biologia (SIUMB) 2019

\section{Correction to: Journal of Ultrasound}

$$
\text { https://doi.org/10.1007/s40477-019-00371-8 }
$$

Unfortunately, all the authors' first name and family name were erroneously switched in the original article and published online.

The complete correct names of the author group are given below.

Paolo Malerba, Daniel Kaminstein, Enrico Brunetti and Tommaso Manciulli

The original article has been corrected.

The original article can be found online at https://doi.org/10.1007/ s40477-019-00371-8.

Tommaso Manciulli

tommaso.manciulli01@ateneopv.it

1 Department of Clinical-Surgical, Diagnostic and Pediatric Sciences, University of Pavia, Viale Brambilla 74, 27100 Pavia, PV, Italy

2 Department of Emergency Medicine, Medical College of Georgia at Augusta University, Augusta, Georgia

3 Department of Infectious Diseases, IRCCS Policlinico San Matteo Hospital Fundation, Pavia, Italy

4 PhD School of Experimental Medicine, University of Pavia, Pavia, Italy 